\title{
A QUALIDADE DO AR EM LISBOA. VALORES MÉDIOS E SITUAÇÕES EXTREMAS
}

HENRIQUE ANDRADE ${ }^{1}$

\begin{abstract}
Resumo - Analisaram-se vários aspectos da qualidade do ar $\left(\mathrm{NO}_{2}\right.$ e $\left.\mathrm{CO}\right)$ em Lisboa: variação espacial da poluição, componente cíclica (anual, semanal e diária) e relação com as condições atmosféricas. No mês de Janeiro de 1993, em que a poluição atingiu níveis muito elevados, encontrou-se uma relação forte entre a qualidade do ar e a velocidade e direcção do vento, por um lado, e a altura da base da inversão térmica sobre Lisboa, às $12 \mathrm{~h}$, por outro. Nos períodos mais poluídos, a velocidade do vento foi inferior a $2 \mathrm{~m} / \mathrm{s}$ em Lisboa/Portela e a inversão térmica situou-se abaixo de $165 \mathrm{~m}$. Quanto à direcção do vento, construíram-se rosas de poluição e verificou-se que os valores mais altos de poluição corresponderam a fluxos favoráveis ao transporte dos poluentes, a partir das principais áreas de emissão.
\end{abstract}

Palavras-chave: poluição atmosférica, Lisboa, $\mathrm{NO}_{2}, \mathrm{CO}$, estabilidade atmosférica, vento.

\begin{abstract}
Air QUality in Lisbon: Mean AND EXTREme values - Different aspects of the air pollution in Lisbon were analised: spatial distribution, cyclical variation (yearly, weekly and daily) and dependence on athmospheric conditions. During January 1993, when air pollution attained very high levels, we found that a strong relationship was established between air pollution and wind speed and direction as well as between air pollution and the height of the thermal inversion over Lisbon. During the more polluted periods, wind speed never reached $2 \mathrm{~m} / \mathrm{s}$ and the thermal inversion was always under $165 \mathrm{~m}$. As for wind direction, pollution roses confirmed that the highest pollution levels occurred with a flux favourable to the transport of pollutants from the main emission areas.
\end{abstract}

Key-words: air pollution, Lisbon, $\mathrm{NO}_{2}, \mathrm{CO}$, atmospheric stability, wind.

A poluição atmosférica é um aspecto importante da degradação do ambiente urbano. Até à década de 60 , as preocupações incidiam sobretudo sobre a poluição industrial (cujo paradigma era o smog londrino), constituída principalmente por compostos de enxofre e partículas. Mais recentemente, o relativo controlo deste tipo de poluição nos países industrializados, o crescimento das áreas urbanas e do parque automóvel, levou à orientação das preocupações dominantes para a poluição de tipo fotoquímico, de que o smog de Los Angeles é o exemplo mais conhecido.

Em Lisboa, o estudo da qualidade do ar encontra numerosas limitações. Até finais da década de 80, os dados eram muito insuficientes, pelo funcionamento irregular dos postos e pela reduzida cobertura espacial da cidade (ALCOFORADO, 1988, 1992); além disso, era feita quase exclusivamente a medição da acidez forte e dos fumos negros. Só nos últimos anos se inciou a recolha sistemática de dados de óxidos de azoto (NOx), monóxido de carbono $(\mathrm{CO})$ e ozono $\left(\mathrm{O}_{3}\right)$. A rede de medição da qualidade do ar de Lisboa, da responsabilidade da Comissão de Gestão do $\mathrm{Ar}$ de Lisboa, foi remodelada e modernizada, tendo sido instalados novos postos, em locais mais adequados às condições actuais (fig. 1, quadro I).

Foi a partir dos dados obtidos em alguns destes postos, que se desenvolveu a investigação que conduziu à dissertação de mestrado "Poluição atmosférica e Clima

\footnotetext{
1 Assistente do Departamento de Geografia da Faculdade de Letras da Universidade Lisboa e investigador do Centro de Estudos Gegráficos. Alameda da Universidade 1699 Lisboa Codex. Tel.: (351-1) 7940218; Fax: (351-1) 7938690
} 
em Lisboa" (ANDRADE, 1994), em que este artigo se baseia. Procura-se analisar alguns aspectos da qualidade do ar em Lisboa, relativamente a dois poluentes atmosféricos: o dióxido de azoto $\left(\mathrm{NO}_{2}\right)$ e o monóxido de carbono $(\mathrm{CO})$. Depois de uma breve abordagem teórica dos factores que condiconam a concentração dos poluentes referidos, caracteriza-se a qualidade do ar em vários locais de Lisboa. O mês de Janeiro de 1993, em que se atingiram níveis de poluição relativamente elevados, é analisado mais detalhadamente, nomeadamente quanto à relação entre a qualidade do ar e as condições atmosféricas.

A concentração de poluentes na atmosfera depende, por um lado, das emissões, condicionadas por factores socio-económicos e, por outro lado, das condições atmosféricas, particularmente o campo de vento e a estrutura vertical da atmosfera (OKE, 1992). Para Lisboa, a variação espacial e temporal destes factores é mal conhecida: não dispondo de informação sobre as emissões e apenas dos dados meteorológicos publicados pelo I.N.M.G, para Lisboa/Portela (quatro observações diárias), a análise da variação da qualidade do ar apresenta, evidentemente, grandes limitações.

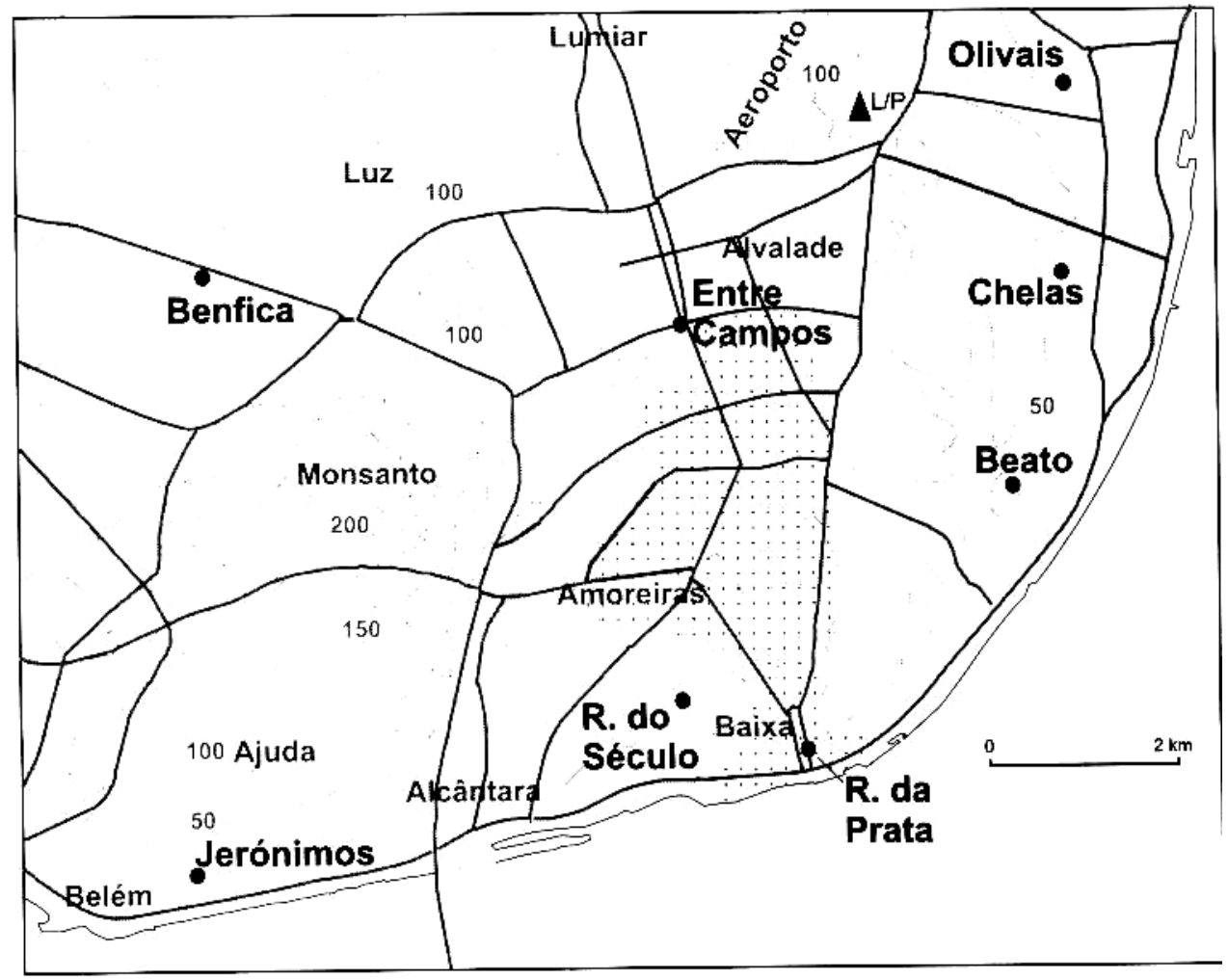

- Beato posto de medição da qualidade do ar

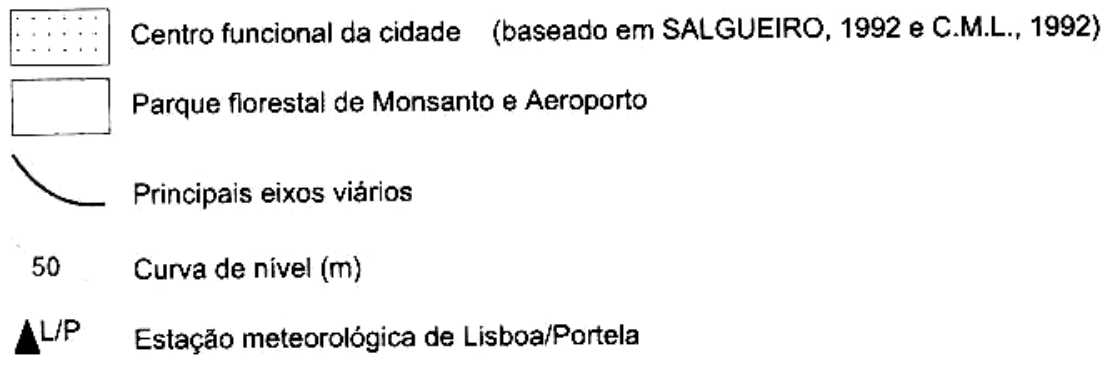

Figura 1 - Rede de medição da qualidade do ar de Lisboa, no semestre de Inverno de 1992/93

Figure 1 - Air quality measurement network in Lisbon, during the winter semester 1992/93. 
Quadro I - Caracterização dos locais onde se situam os postos de medição da qualidade do ar Table I - Air quality measuring points

\begin{tabular}{|c|c|c|}
\hline Postos & Características urbanas & Posição topográfica \\
\hline Olivais & $\begin{array}{c}\text { Escola secundária em área residencial com espaços } \\
\text { verdes }\end{array}$ & vertente exposta a $\mathrm{E}$ \\
\hline Chelas & $\begin{array}{c}\text { Escola primária em área residencial com espaços } \\
\text { verdes }\end{array}$ & vertente exposta a $\mathrm{E}$ \\
\hline Beato & $\begin{array}{l}\text { Escola secundária em área residencial, com espaços } \\
\text { verdes, próximo de área industrial. }\end{array}$ & vertente exposta a $\mathrm{E}$ \\
\hline Entre Campos & $\begin{array}{l}\text { Área aberta, com grande circulação e junto a termi- } \\
\text { nal rodoviário muito activo. }\end{array}$ & posição deprimida \\
\hline Benfica & $\begin{array}{l}\text { Área residencial e comercial com tráfego intenso; } \\
\text { cruzamento da Estrada de Benfica (orientação ESE- } \\
\text {-WNW), com transversal perpendicular. }\end{array}$ & posição deprimida \\
\hline Rua da Prata & $\begin{array}{l}\text { Área comercial com com tráfego intenso; cruza- } \\
\text { mento da Rua da Prata (orientação NNW-SSE) com } \\
\text { transversal perpendicular }\end{array}$ & posição deprimida \\
\hline Rua do Século & $\begin{array}{l}\text { Área residencial densa com pouco tráfego e ruas } \\
\text { estreita. O posto situa-se sobre um edifício }\end{array}$ & vertente exposta a SW \\
\hline
\end{tabular}

\section{1 - A TRAJECTÓRIA DOS POLUENTES ATMOSFÉRICOS}

Os poluentes atmosféricos têm uma trajectória, desde a sua emissão até à recepção pelos seres vivos ou pela superfície (fig. 2), cujas principais fases são aqui descritas, no que se refere aos poluentes estudados: $\mathrm{NO}_{2}$ e $\mathrm{CO}$.

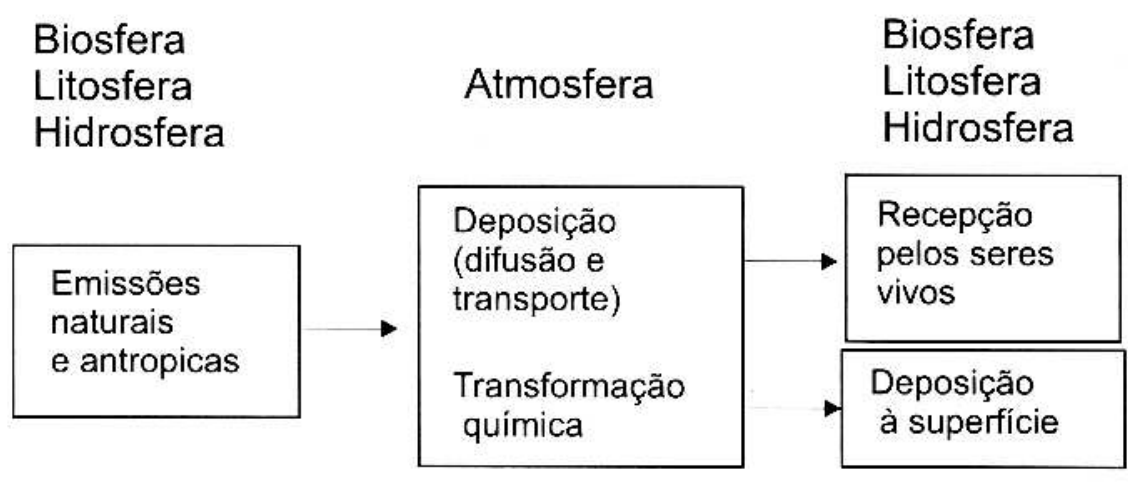

Figura 2 - Trajectória dos poluentes atmosféricos (baseado em OKE, 1993 e JANOUEIX-YACONO, 1993)

Figure 2 - Air pollution trajectories.

\section{1 - As emissões}

As principais fontes antrópicas de $\mathrm{NO}_{2}$ e $\mathrm{CO}$ são os veículos automóveis, embora, relativamente ao $\mathrm{NO}_{2}$, devam também ser consideradas a indústria e a produção de energia termoelétrica.

Os óxidos de azoto (NOx), são emitidos essencialmente sob a forma de NO, na sequência de combustões a alta temperatura. $\mathrm{O} \mathrm{NO}_{2}$ forma-se por oxidação espontânea do NO, poucos segundos após a saída dos gases do escape, através da reacção 2 $\mathrm{NO}+\mathrm{O}_{2} \rightarrow 2 \mathrm{NO}_{2}$ (EnVIRONMENTAl PRotection Agency, 1971). O CO resulta da combustão incompleta da mistura ar/gasolina, sendo um poluente típico de locais com tráfego congestionado (JOUMARD, 1984).

A evolução das emissões de $\mathrm{NO}_{2}$ e $\mathrm{CO}$ tem sido diferente. Em várias cidades da Europa industrializada, o monóxido de carbono tem decrescido de forma acentuada; 
pelo contrário, as emissões de NOx não apresentam uma tendência para redução significativa, devido ao crescimento do parque automóvel, nomeadamente dos veículos de grande cilindrada (Stroebel, 1992; BAVAY e Roussel, 1993). Em Portugal, prevê-se um aumento das emissões de NOx de 4 a $8 \%$ até 1997, seguido de uma estabilização e um ligeiro decréscimo até 2005 (BORREGO et al., 1991; PINHO e SEIXAS, 1993).

\section{2 - A transformação dos poluentes na atmosfera}

As reacções fotoquímicas, iniciadas na presença de óxidos de azoto e hidrocarbonetos (também de origem principalmente automóvel) conduzem à formação de $\mathrm{O}_{3} \mathrm{e}$ outros compostos. $\mathrm{O} \mathrm{NO}_{2}$ reage com os hidrocarbonetos, podendo, na presença de forte radiação solar, originar-se o smog fotoquímico, com elevadas concentrações de $\mathrm{O}_{3}$ e redução da proporção de NOx; por outro lado, uma elevada proporção de NOx na atmosfera leva à destruição do $\mathrm{O}_{3}$ e ao incremento da quantidade de $\mathrm{NO}_{2}(\mathrm{COMRIE}$, 1990).

\section{3 - A dispersão e remoção dos poluentes atmosféricos}

A dispersão dos poluentes na atmosfera inclui dois processos: o transporte, dependente dos movimentos organizados do ar, a diferentes escalas, e a difusão ${ }^{2}$, devida à turbulência térmica ou forçada (MORAN e PORTELLI, 1987). Estes processos dependem da interacção entre os factores atmosféricos (sobretudo a estratificação térmica e o campo de vento), as condições de emissão e as características da superfície (nomeadamente a topografia) (OKE, 1992).

A estratificação térmica da atmosfera condiciona a dispersão vertical dos poluentes. As situações de maior estabilidade são características de noites de forte arrefecimento radiativo da superfície, ou devidas ao contacto das massas de ar com superfícies mais frias. As condições mais favoráveis a uma forte concentração de poluentes corrrespondem às inversões térmicas, cuja origem pode ser diversa; em Lisboa assumem especial importância as inversões de subsidência, sobretudo no Verão (84 a $89 \%$ do total das inversões témicas, às $12 \mathrm{~h}$, entre Julho e Setembro - FERREIRA, 1991). Não é suficientemente conhecida a influência da cidade sobre a estabilidade vertical da atmosfera; contudo, o lançamento de balões estabilizados em alguns dias de Verão, permitiu observar a existência de uma camada de ar instável, de cerca de 400m de espessura, sobre o centro de Lisboa (ALCOFORADO, 1992).

A relação entre a estrutura térmica da baixa troposfera e a altura das emissões ${ }^{3}$ permite distinguir situações típicas de dispersão, habitualmente representadas através do aspecto momentâneo da trajectória dos poluentes, emitidos por uma chaminé industrial (fig. 3). As condições de maior estabilidade (fig. 3B) são particularmente favoráveis à concentração das emissões dos veículos automóveis, junto ao solo. Ao contrário do que seria de supor, para as emissões a partir de chaminés industriais, as situações de alguma instabilidade (fig. 3C) podem favorecer fortes concentrações dos poluentes emitidos abaixo da base da inversão térmica; os poluentes ficam retidos na camada de ar instável, pouco espessa. Estas situações são típicas do início da

\footnotetext{
2 De acordo com OKe (1992, p. 114) e a O.M.M. (cit. por WANTA, 1968, p. 187), a difusão pode ser definida como a troca de parcelas de um fluido entre sectores da atmosfera, num movimento de caracácter aleatório, numa escala frequentemente molecular.

3 A "altura efectiva" da emissão $(\mathrm{H})$ é igual a $\mathrm{hg}+\mathrm{Dh}$, sendo hg a altura da fonte e Dh função da temperatura e velocidade da emissão (RIBAS, 1979)
} 
destruição, pela base, da inversão térmica nocturna, devido ao aquecimento da superfície, durante a manhã (PASQUILL, 1974).

O vento tem uma acção de transporte e difusão dos poluentes (OKE, 1992). O transporte depende do "vector médio do vento" (definido pela direcção e velocidade em períodos superiores a uma hora); a difusão é principalmente condicionada pela turbulência, correspondente às variações de velocidade e rumo em curtos períodos de tempo (RIBAS, 1979).

A velocidade do vento é o principal factor de dispersão, em meio urbano (PISSIMANIS et alli, 1991). Condiciona o volume de ar em que os poluentes se vão difundir e a distância de transporte; contudo, um aumento da velocidade pode ter um efeito negativo sobre a qualidade do ar, ao reduzir a altura efectiva das emissões. A direcção do vento é, evidentemente, o factor que determina quais os locais mais afectados pelas emissões de diferentes fontes (RIBAS, 1979; OKE, 1992).

As características da turbulência dependem também da estrutura térmica da atmosfera: em condições neutras ou estáveis, a turbulência é sobretudo mecânica (dependendo da rugosidade da superfície) e tende a ser limitada verticalmente; em condições instáveis, a turbulência é principalmente térmica e predominam os movimentos verticais (MORAN e PORTELLI, 1987).
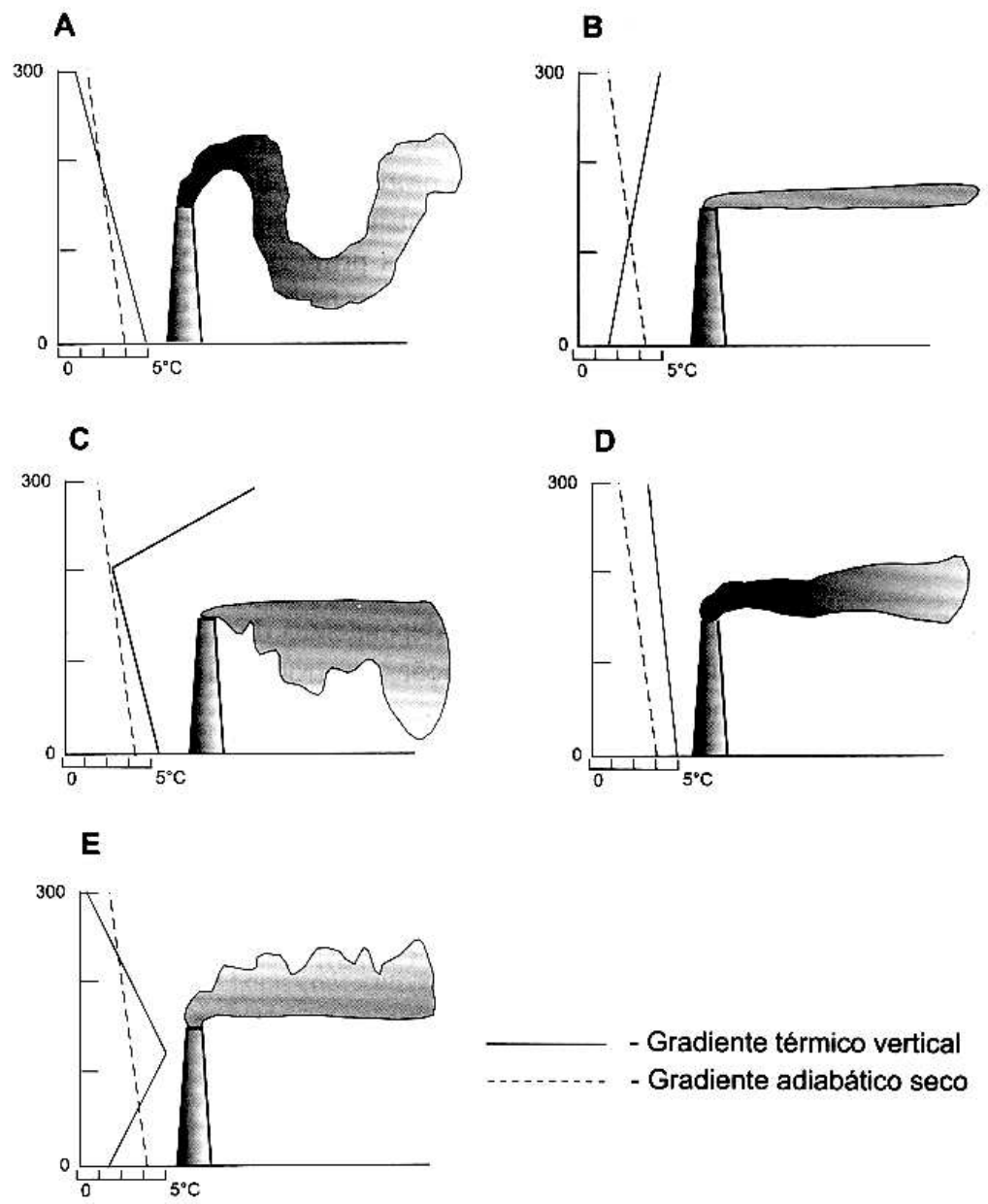

Figura 3 - Trajectória típica dos poluentes industriais em diferentes situações de estabilidade da atmosfera (baseado em PASQUILL, 1974 e OKE, 1992)

Figure 3 - Industrial pollutants trajectories versus atmospheric stability. 
Os mecanismos de dispersão dos poluentes actuam a diferentes escalas, temporais e espaciais. Segundo MORAN e PORTELLI (1987) podemos distinguir:

- Na escala microclimática, os fenómenos de dispersão resultantes da interacção dos fluxos atmosféricos com a superfície, são particularmente importantes nas áreas urbanas ou de relevo acidentado;

- Na escala macroclimática, assume particular importância o transporte dos poluentes a longa distância, determinado pelo campo de vento horizontal; este processo pode-se associar a fenómenos de transformação química e de remoção dos poluentes, levando à degradação dos ecossistemas e dos edifícios, a grande distância das fontes de emissão (WINCHESTER, 1987a);

- Na escala intermédia, consideram-se os sistemas atmosféricos de circulação local ou condicionados pelos espaços urbanos. Os primeiros podem ser determinados directamente pelo relevo (ventos do tipo Föhn ou fenómenos de canalização) ou por contrastes térmicos locais (fenómenos de drenagem do ar frio e brisas); este último tipo de circulação é, em geral, considerado negativo para a dispersão dos poluentes, devido ao seu carcácter cíclico e fechado e à reduzida velocidade do vento. Os contrastes térmicos urbanos podem igualmente originar sistemas de circulação local, convergentes para o centro da cidade (habitualmente designados "brisas do campo"), que levam ao aumento da concentração dos poluentes, nessa área (OKE, 1992).

Os fenómenos meso ou microclimáticos, dependentes da diferenciação térmica local, assumem especial importância em situações macroclimáticas de estabilidade atmosférica, com fluxo sinóptico fraco.

A remoção dos poluentes gasosos da atmosfera pode fazer-se por deposição seca, através da adesão a superfícies ou absorção pelas plantas, ou por deposição húmida, com dissolução nas gotas de chuva, no processo da sua formação (rainout), ou já nas gotas em queda (rainwash). Este último mecanismo é considerado o mais eficaz na remoção dos poluentes (WINCHESTER, 1987b).

\section{2 - A QUALIDADE DO AR EM LISBOA}

A qualidade do ar em Lisboa é habitualmente considerada boa, comparativamente com a de outras cidades europeias. A divulgação diária de valores de concentração de poluentes, recolhidos na Rua do Século, contribui para essa ideia. Contudo, este posto situa-se num local elevado e distante das principais áreas de emissão de poluentes (quadro I, fig. 1), dando uma imagem demasiado favorável da poluição atmosférica em Lisboa. A comparação dos valores registados na Rua do Século com os de locais com tráfego intenso permite confirmar o que foi dito.

A qualidade do ar nos diferentes postos, em Lisboa, foi caracterizada através das curvas de distribuição de frequências dos valores médios diários de concentração de $\mathrm{NO}_{2}$ e $\mathrm{CO}$ e, de um indicador dos valores extremos, o percentil 98 (valor ultrapassado em $2 \%$ dos casos). O estudo incidiu apenas sobre o semestre de Inverno (1 de Outubro a 31 de Março), dispondo-se de duas séries com diferente duração:

- Semestre de Inverno de 1992/93, com dados de 8 postos de medição da qualidade do ar (fig. 1). Devido à reduzida duração do período estudado, os resultados devem ser apenas considerados como indicativos.

- Semestres de Inverno entre 1989 e 1993, para os quais se dispõe apenas de valores da Rua do Século. 
Como referência, são considerados os limiares definidos pela legislação portuguesa para a concentração dos poluentes (quadro II).

Quadro II - Limiares legais de concentração de $\mathrm{NO}_{2}$ e $\mathrm{CO}$ na atmosfera

Table II - Legal limits of $\mathrm{NO}_{2}$ and $\mathrm{CO}$ atmospheric concentration

\begin{tabular}{|c|c|c|}
\hline NO2 & \multicolumn{2}{|c|}{$\left(\mu \mathrm{g} / \mathrm{m}^{3}\right)$} \\
\hline Valor guia (obtido a partir dos valores horários) & mediana & 50 \\
\cline { 2 - 3 } & percentil 98 & 135 \\
\hline Valor limite (obtido a partir dos valores horários) & percentil 98 & 200 \\
\hline $\begin{array}{c}\text { Valor guia para um período de 24 h (estabelecido pela Or- } \\
\text { ganização Mundial de Saúde) }\end{array}$ & média & 150 \\
\hline CO & & \\
\hline Valor limite para 1 hora & média & 40 \\
\hline Valor limite para 8 horas consecutivas & média & 10 \\
\hline Valor guia para 24 h & média & 1 \\
\hline Fontes: Portaria n n $^{\mathbf{0}} 268 / 93$ de 12 de Março; C.G.A.L. (1993, 1994) \\
\hline
\end{tabular}

\section{1 - A qualidade do ar na Rua do Século}

Os níveis de concentração média diária de $\mathrm{NO}_{2}$ na Rua do Século foram relativamente baixos (fig. 4). O limiar diário de $150 \mu \mathrm{g} / \mathrm{m}^{3}$ nunca foi ultrapassado, nos Invernos entre 1989 e 1993 e o percentil 98 foi apenas de $73 \mu \mathrm{g} / \mathrm{m}^{3}$, muito inferior aos limiares legais (quadro I). 

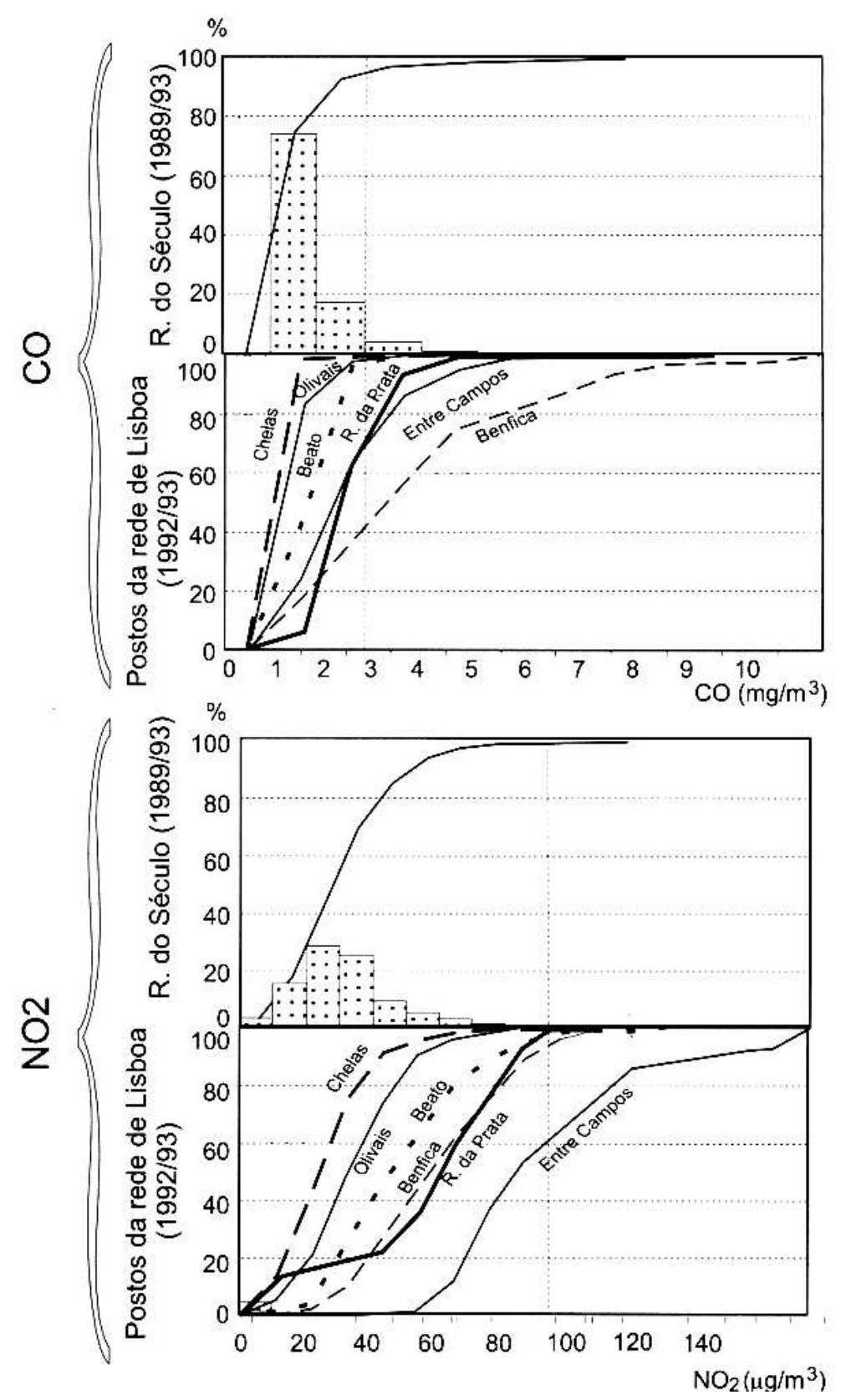

Figura 4 - Concentração média diária de poluentes no semestre de Inverno Fonte: D.G.Q.A.; C.G.A.L.

Figure 4 - Mean daily air pollution in Lisbon during the winter semester. 
A violação do limiar legal de CO para os valores diários $\left(1 \mathrm{mg} / \mathrm{m}^{3}\right)$ foi muito mais frequente, tendo ocorrido em 25\% dos dias (fig. 4); o percentil 98 foi de $3.65 \mathrm{mg} / \mathrm{m}^{3}$. Pode-se portanto considerar que, neste local, os principais problemas de poluição atmosférica foram colocados pelo monóxido de c. rbono.

\section{2 - A qualidade do ar nos postos da rede de Lisboa}

A distribuição das frequências dos valores médios diários de concentração de $\mathrm{NO}_{2}$ e $\mathrm{CO}$ (fig. 4), permite distinguir os locais com grande intensidade de tráfego Entre Campos, Benfica e Rua da Prata - com níveis de poluição claramente superiores, quer aos da Rua do Século, quer aos da área oriental da cidade (Beato, Chelas e Olivais). Contudo, para os valores extremos de $\mathrm{NO}_{2}$, o posto do Beato aproximou-se do da Rua da Prata (o percentil 98 foi quase igual nos dois postos - cerca de 85 $\mu \mathrm{g} / \mathrm{m}^{3}$ ). Entre Campos destacou-se pelos níveis muito elevados de poluição por $\mathrm{NO}_{2} \mathrm{e}$ Benfica por CO.

Em Entre Campos ocorreram concentrações médias diárias de $\mathrm{NO}_{2}$ superiores a $150 \mu \mathrm{g} / \mathrm{m}^{3}$, em $7 \%$ dos dias, e superiores a $500 \mu \mathrm{g} / \mathrm{m}^{3}$, em 7 dias; nos outros postos, raramente foi ultrapassado o valor de $100 \mu \mathrm{g} / \mathrm{m}^{3}$. Considerando o percentil 98, Entre Campos destacou-se ainda mais $\left(557 \mu \mathrm{g} / \mathrm{m}^{3}\right.$; Benfica, o segundo posto com valor mais elevado, atingiu apenas $93 \mu \mathrm{g} / \mathrm{m}^{3}$ ).

A violação do limiar legal de concentração média diária de $\mathrm{CO}$ foi muito frequente nos três locais mais poluídos (fig. 4); pelo contrário, só ocorreu em $18 \%$ dos dias, no posto dos Olivais e em $2 \%$, em Chelas. Os níveis mais elevados de poluição por monóxido de carbono ocorreram em Benfica, com concentrações superiores a $10.5 \mathrm{mg} / \mathrm{m}^{3} \mathrm{em} 2 \%$ dos dias, valor nunca atingido nos outros locais.

O tratamento estatístico dos valores médios horários foi feito pela Comissão de Gestão do Ar de Lisboa (1994), num relatório divulgado posteriormente à entrega da dissertação de mestrado, no âmbito da qual se iniciou o trabalho aqui apresentado. $\mathrm{O}$ período tratado foi, para alguns postos, diferente do aqui analisado. Os resultados não diferem muito dos que foram obtidos, para as médias diárias, no presente trabalho. Destacaram-se nos dois casos, pelos valores elevados, os postos de Entre Campos, Benfica e Rua da Prata. O primeiro salientou-se sobretudo pelos valores extremos de concentração de $\mathrm{NO}_{2}$, sendo o único em que o percentil 98 das concentrações médias horárias ultrapassa o valor limite $\left(200 \mu \mathrm{g} / \mathrm{m}^{3}\right)$; as médias horárias de $\mathrm{CO}$ apenas ultrapassam o limite legal $\left(40 \mathrm{mg} / \mathrm{m}^{3}\right)$ durante duas horas, em Benfica, apesar de as médias diárias serem, com muita frequência, superiores ao valor guia, como foi visto.

As concentrações extremamente elevadas de $\mathrm{NO}_{2}$, em Entre Campos, devem-se à localização do posto, junto a um terminal rodoviário (além de se situar numa área de intensa circulação automóvel). Os veículos a Diesel, que utilizam o terminal, emitem muito menos $\mathrm{CO}$ do que os veículos a gasolina, enquanto as emissões de $\mathrm{NO}_{2}$ são semelhantes, para os dois tipos de motores (VASCONCELOS e NEVES, 1988); isto pode justificar a diferença entre os dois poluentes, neste local.

A correlação entre os valores registados em Entre Campos, Rua da Prata e Benfica é muito mais forte para o $\mathrm{CO}$ do que para o $\mathrm{NO}_{2}$ (quadro III); isto indica a maior importância, para o dióxido de azoto, das particularidades locais nas condições de emissão e dispersão. Relativamente ao $\mathrm{NO}_{2}$, a relação entre Entre Campos e os outros locais não chega a ser estatisticamente significativa, o que reflecte as características, já referidas, da localização daquele posto. 
Quadro III - Coeficientes de correlação das concentrações médias diárias de $\mathrm{NO}_{2}$ e de CO

Table III - Correlation coefficients referring to daily mean pollutant concentrations

\begin{tabular}{|c|c|c|c|c|}
\hline & \multicolumn{2}{|c|}{$\mathrm{NO}_{2}$} & \multicolumn{2}{|c|}{$\mathrm{CO}$} \\
\hline Postos & Entre Campos & Benfica & Entre Campos & Benfica \\
\hline Entre Campos & 1 & 0.13 & 1 & 0.37 \\
\hline Benfica & 0.13 & 1 & 0.37 & 1 \\
\hline Rua da Prata & 0.2 & 0.32 & 0.37 & 0.64 \\
\hline
\end{tabular}

Para compreender outros aspectos da variação espacial da poluição em Lisboa faltam dados, quer sobre as emissões (nomeadamente a intensidade e características do tráfego), quer sobre as condições de dispersão dos poluentes. Particularmente importantes são o conhecimento do campo de vento sobre a cidade, em diferentes condições sinópticas, a compreensão dos mecanismos das brisas (já estudados, para o Verão, por ALCOFORADO, 1987) geradas pela interacção entre os campos térmicos da cidade e do estuário, e as relações entre a ilha de calor urbano e a estrutura térmica da atmosfera, sobre Lisboa, para a qual não existem dados.

\section{3 - As variações cíclicas da qualidade do ar}

A variação temporal da qualidade do ar pode apresentar uma componente cíclica (de carácter anual, semanal ou diário), resultante da combinação da variação das emissões com a das condições atmosféricas (OKE, 1992). Neste trabalho, só foi possível analisar a variação anual da poluição na Rua do Século, dado ser o único posto com registos num período suficientemente longo.

Embora os factores que condicionam a formação de $\mathrm{NO}_{2}$ (intensidade da radiação solar e duração da insolação) tenham maior intensidade no Verão, a concentração deste poluente é, com muita frequência, superior no Inverno, devido à maior estabilidade da atmosfera e ao incremento das combustões, nesta estação (ENVIRONMENTAl PRotection AgEncy, 1971). Por outro lado, é no Verão que a formação de $\mathrm{O}_{3}$, no decurso do ciclo fotoquímico e a expensas do $\mathrm{NO}_{2}$, tem maior importância; este facto contribui para a diminuição da proporção de NOx na atmosfera. Em Lisboa, entre 1981 e 1989, as maiores concentrações de $\mathrm{O}_{3}$ foram também registadas no Verão (FERREIRA, 1991).

A variação da poluição por $\mathrm{NO}_{2}$, entre 1989 e 1993, na Rua do Século, não apresentou uma tendência sazonal clara (fig. 5a). Note-se, contudo, que os valores de concentração, neste posto, são baixos, com contrastes pouco significativos. No semestre de Inverno de 1992/93, as concentrações mais elevadas de $\mathrm{NO}_{2}$ ocorreram em Janeiro, em quase todos os postos da rede de Lisboa da C.G.A.L, enquanto na Rua do Século, os valores mais elevados se registaram em Outubro. 


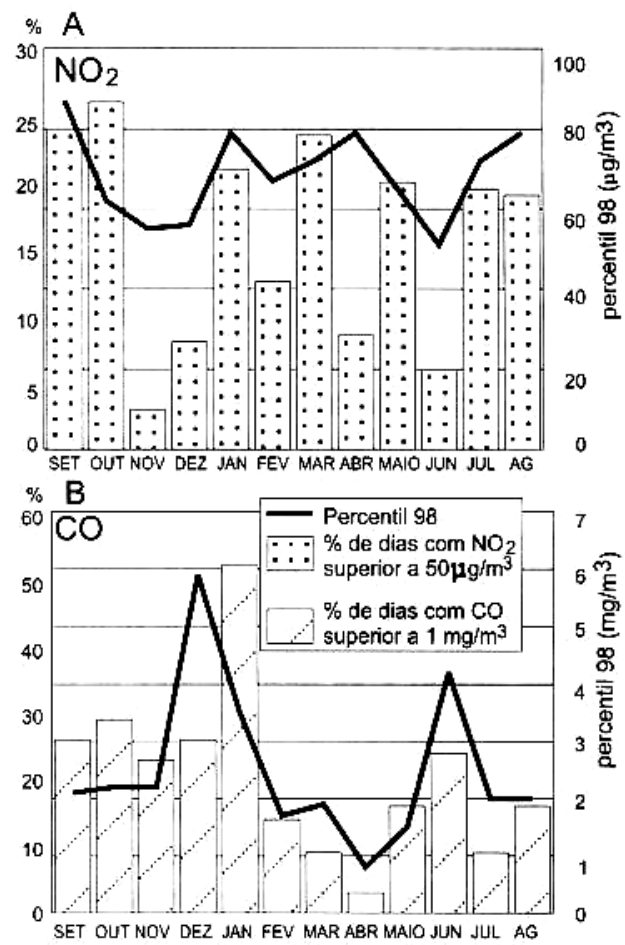

Figura 5 - Variação anual da qualidade do ar na R. do Século (1989/93) Fonte: D.G.Q.A.

Figure 5 - Air quality in Lisbon (R. do Século) between 1989 and 1993.

Os valores mais elevados de concentração de $\mathrm{CO}$ foram registados nos meses de Dezembro e Janeiro (fig. 5b). Dezembro destacou-se pelos valores extremos, o que se poderá dever à intensidade do tráfego, particularmente no período que precede o Natal; Janeiro apresentou uma elevada frequência de dias muito poluídos, devido possivelmente ao predomínio de situações de estabilidade durante este mês, nos anos estudados (em 58\% dos dias de Janeiro ocorreram situações anticiclónicas).

Vários autores encontraram uma elevada regularidade semanal na variação da concentração de poluentes (ENVIRONMENTAL PROTECTION AgENCY, 1971; ESCOURROU, 1991 e MoNTEIRO, 1989). Os resultados obtidos neste trabalho não foram muito esclarecedores, quanto a este aspecto; o facto mais saliente foi a redução da poluição ao domingo. A reduzida duração do período estudado, para os postos da rede de Lisboa da C.G.A.L, terá sido a principal limitação a esta análise.

A combinação dos ritmos diários das actividades humanas e das condições climáticas pode contribuir para a ocorrência de dois picos de poluição, correspondentes, aproximadamente, às horas de ponta (OKE, 1992). Esse ciclo típico pode, no entanto, ser alterado, pelas condições meteorológicas ou por modificações no ritmo das actividades poluentes. A formação de $\mathrm{O}_{3}$ tem o seu máximo por volta das $12 \mathrm{~h}$, devido à maior intensidade de radiação solar, contribuindo para a redução do teor de NOx; por outro lado, durante as horas de ponta, a elevada proporção de óxidos de azoto na atmosfera contribui para a destruição do $\mathrm{O}_{3}$ (através da reacção $\mathrm{NO}_{2}+\mathrm{O}_{3} \rightarrow \mathrm{NO}_{3}+\mathrm{O}_{2}$, CARlier e Mouvier, 1988). Em Lisboa, a concentração de $\mathrm{O}_{3}$ apresenta também, como padrão mais frequente, um máximo por volta das 12 h (FERREIRA, 1991).

Na maior parte dos dias do semestre de Inverno de 1992/93, observaram-se dois máximos de concentração de poluentes: entre as $7 \mathrm{~h}$ e as $9 \mathrm{~h}$, aproximadamente e 
entre as $17 \mathrm{~h}$ e as $20 \mathrm{~h}$; os valores da tarde foram, na maior parte dos dias, superiores aos da manhã. Observou-se contudo uma diferenciação espacial (figs. 6a e 6b), condicionada pelos diferentes padrões de actividades ao longo do dia nos vários locais: na Baixa, por exemplo, para o $\mathrm{NO}_{2}$, o pico da manhã apresentou uma menor importância e um início mais tardio; o da tarde iniciou-se mais cedo do que nos outros locais, (cerca das 14 h, enquanto em Benfica e Entre Campos, os valores só aumentam acentuadamente a partir das 17 h). Em Benfica, os dois máximos de concentração de CO foram de importância muito semelhante.

A explicação das diferenças entre os vários postos, quanto ao ritmo diário de variação da qualidade do ar, exigiria uma análise baseada na variação da intensidade e características do tráfego, ao longo do dia. Todavia, deve ser considerado o facto de a Baixa ser um local de chegada da migração pendular diária (portanto com um afluxo de tráfego mais tardio do que os outros locais), enquanto Entre Campos e Benfica são sobretudo local de passagem ou de partida. Por outro lado, o padrão geral sofreu frequentes modificações, nomeadamente em alguns dias muito poluídos de Janeiro de 1993, que adiante serão analisados com maior detalhe.

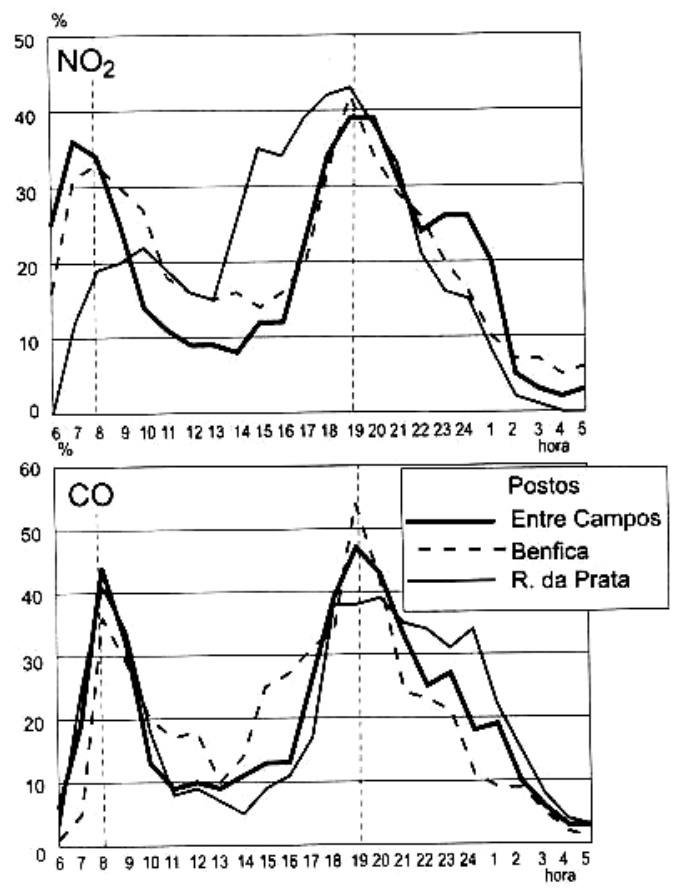

Figura 6 - Concentração diária de poluentes no semestre de Inverno de 1992/93

(\% das horas com concentração média de poluentes superior ao $8^{\circ}$ decil das concentrações médias horárias). Fonte: C.G.A.L.

Figure 6 - Daily pollution in Lisbon, during the winter semester 1992/93; percentage of hours, in which pollution values exceed the mean hourly concentration $8^{\text {th }}$ decil.

\section{3 - O MÊS DE JANEIRO DE 1993}

Os níveis mais baixos de qualidade do ar em Lisboa, no semestre de Inverno de 1992/93, registaram-se em Janeiro. O limiar legal para as concentrações médias diárias de $\mathrm{CO}$ (quadro II) foi ultrapassado todos os dias do mês em Entre Campos, Benfica e Rua da Prata, em 18 dias em Chelas e em 11 dias nos Olivais. O valor absoluto mais elevado foi registado em Benfica, no dia 8 , com $18.1 \mathrm{mg} / \mathrm{m}^{3}$. 
Os valores médios diários de $\mathrm{NO}_{2}$ foram superiores aos habituais, embora tenham permanecido, quase sempre, abaixo do valor guia de $150 \mu \mathrm{g} / \mathrm{m}$. Só em Entre Campos, a concentração de dióxido de azoto foi muito superior àquele valor (ultrapassado-o em 11 dias). Registaram-se valores superiores a $500 \mu \mathrm{g} / \mathrm{m}^{3} \mathrm{em} 7$ dias de Janeiro de 1993 (a média mais elevada ocorreu no dia 9: $789 \mu \mathrm{g} / \mathrm{m}^{3}$ ).

Ao longo do mês, os níveis mais elevados dos dois poluentes não ocorreram simultâneamente em todos os postos. Entre Campos diferenciou-se, não só pela concentração de $\mathrm{NO}_{2}$, mas também pelo ritmo de variação da qualidade do ar. Durante o mês de Janeiro, foi possível distinguir três períodos particularmente poluídos (fig. 7):

- Entre 4 e 10 de Janeiro, registaram-se as concentrações de $\mathrm{CO}$ e $\mathrm{NO}_{2}$ mais fortes do semestre, com os valores máximos no dia $8 \mathrm{em}$ quase todos os locais e, no dia 9, em Entre Campos $\left(\mathrm{NO}_{2}\right.$.). Neste local, a concentração média de $\mathrm{NO}_{2}$ aumentou acentuadamente entre os dias 8 e $9\left(\right.$ de $228 \mu \mathrm{g} / \mathrm{m}^{3}$ para $\left.789 \mu \mathrm{g} / \mathrm{m}^{3}\right)$, mantendo-se acima dos $400 \mu \mathrm{g} / \mathrm{m}^{3}$ até ao dia 11. Considerando os valores normalizados, que possibilitam a comparação entre os dois poluentes e os vários postos, o nível de poluição em Entre Campos, no dia 9, destaca-se ainda mais.

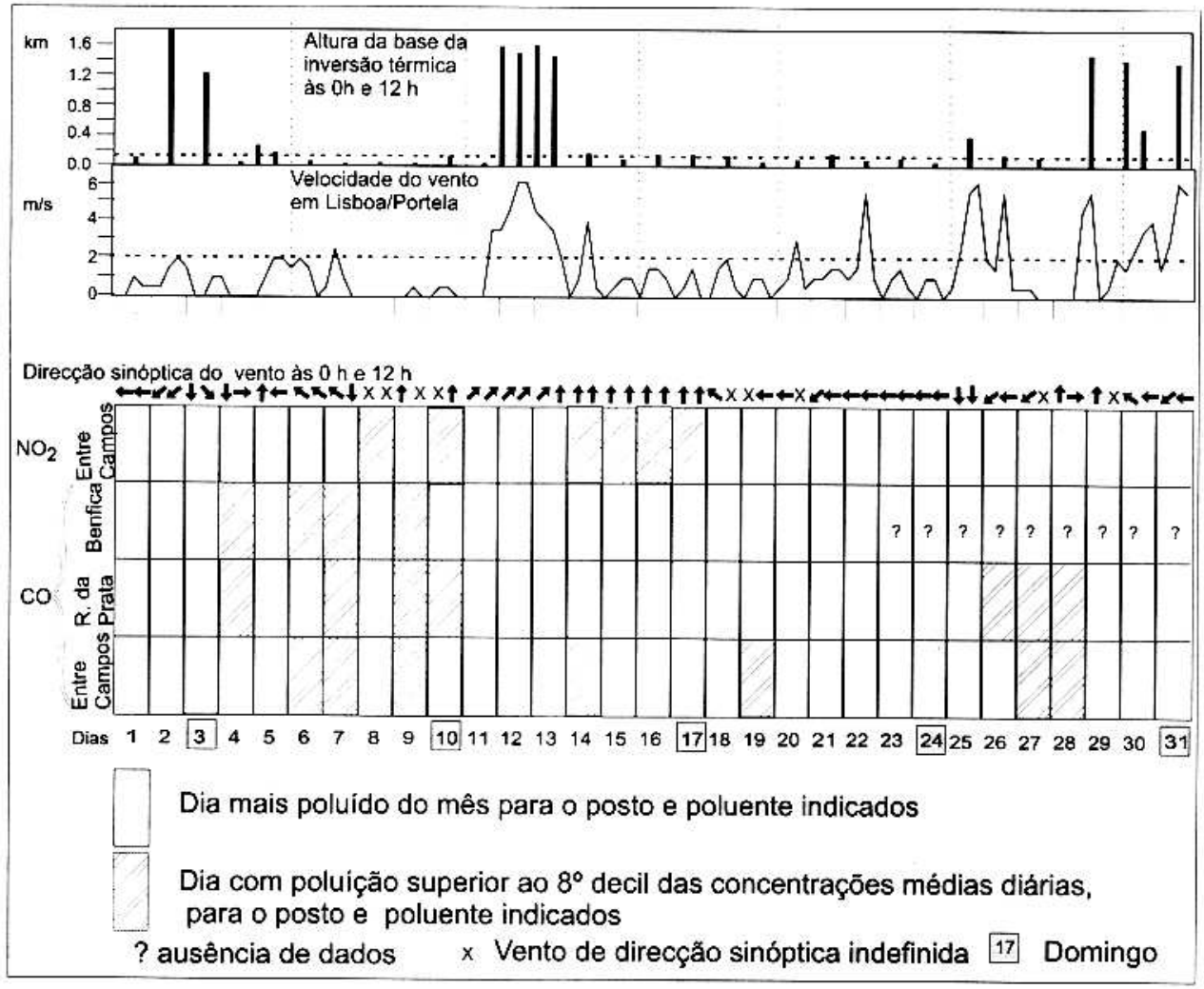

Figura 7 - Qualidade do ar e condições atmosféricas em Lisboa, em Janeiro de 1993 Fontes: C.G.A.L.; I.N.M.G.

Figure 7 - Air quality versus weather, during January 1993. 
Quadro IV - Concentração de $\mathrm{CO}$ e $\mathrm{NO}_{2}$ em Lisboa, nos dias 8 e 9 de Janeiro de 1993

(valores normalizados)

Table IV - CO and $\mathrm{NO}_{2}$ concentration in Lisbon, on 8 and 9 January 1993

\begin{tabular}{|c|c|c|c|c|}
\hline & \multicolumn{2}{|c|}{$\mathrm{CO}$} & \multicolumn{2}{|c|}{$\mathrm{NO}_{2}$} \\
\hline Postos & $\operatorname{dia} 8$ & $\operatorname{dia} 9$ & $\operatorname{dia} 8$ & $\operatorname{dia} 9$ \\
\hline Entre Campos & 5.93 & 2.9 & 1.24 & 6.85 \\
\hline Benfica & 5.83 & 1.75 & 2.16 & 0.94 \\
\hline Rua da Prata & 4.8 & 2.92 & 1.59 & 0.51 \\
\hline
\end{tabular}

- Nos dias 14 a 17, voltou a registar-se forte poluição (fig. 7), sobretudo em Entre Campos $\left(552 \mu \mathrm{g} / \mathrm{m}^{3}\right.$ de $\mathrm{NO}_{2}$, no dia 16). A concentração de $\mathrm{CO}$ foi também elevada, embora em geral inferior ao $8^{\circ}$ decil; os valores em Entre Campos foram muito próximos dos de Benfica, ao contrário do habitual $\left(3.93 \mathrm{mg} / \mathrm{m}^{3} \mathrm{em}\right.$ Entre Campos e $3.90 \mathrm{mg} / \mathrm{m}^{3}$ em Benfica, no dia 14; a média do semestre foi de $1.86 \mathrm{mg} / \mathrm{m}^{3}$ no primeiro posto referido, $3.26 \mathrm{mg} / \mathrm{m}^{3}$ no segundo).

- Nos dias 26 a 28 de Janeiro, as concentrações de CO foram elevadas em Entre Campos e na Rua da Prata, (o posto de Benfica não funcionou, neste período).

Os elevados níveis de poluição verificados no mês de Janeiro, só se podem explicar pela coincidência de fortes emissões e de condições atmosféricas propícias à concentração dos poluentes. Relativamente ao primeiro aspecto, não existem dados. É contudo provável que as características diferenciadas da variação da concentração de $\mathrm{NO}_{2}$, em Entre Campos, se devam, sobretudo, ao ritmo da actividade do terminal rodoviário, cuja importância foi já apontada.

Durante o mês de Janeiro predominaram condições atmosféricas de estabilidade. Portugal esteve, quase todo o mês, sob influência de um anticiclone centrado sobre a Península Ibérica e o Mediterrâneo Ocidental, com um fraco gradiente de pressão e forte estabilidade vertical da atmosfera. A situação modificou-se a partir do dia 28, mantendo-se as condições de instabilidade até ao final do mês.

É evidente a relação dos níveis mais elevados de poluição com os valores mais baixos de velocidade do vento e a maior estabilidade vertical da atmosfera. Nos dias mais poluídos (fig. 7), a velocidade do vento em Lisboa/Portela foi inferior a $2 \mathrm{~m} / \mathrm{s}$ em quase todas as observações e a base da inversão térmica às $12 \mathrm{~h}$ situou-se, no máximo, a 165m de altura (em 8 dos 13 dias abaixo de $100 \mathrm{~m}$ ). Os dias 8 e 9 de Janeiro, que registaram os níveis de poluição mais altos, foram também os mais frios do mês (mínimas de $3^{\circ} \mathrm{C}$ e máximas de $8^{\circ} \mathrm{C}$, em Lisboa/Portela); o nevoeiro manteve-se nestes dias pelo menos até às $12 \mathrm{~h}$. $\mathrm{O}$ forte arrefecimento nocturno e a persistência de temperaturas baixas ao longo do dia, associados à presença do nevoeiro, contribuiram decerto para o reforço da estabilidade da camada limite.

A relação com a direcção do vento é particularmente óbvia em Entre Campos. Nos dias mais poluídos, o fluxo sinóptico ${ }^{4}$ teve direcção indefinida (coincidindo frequentemente com condições de calma) ou foi do quadrante $S$. A influência desta direcção do vento no aumento da poluição, muito evidente nos dias 14 a 17 (fig. 7), compreende-se facilmente, por este posto se situar a $\mathrm{N}$ das áreas de maior emissão de poluentes. Conclui-se que os elevados níveis de poluição, em Entre Campos, não se devem apenas às emissões locais, mas também ao transporte a partir de outras áreas.

Nos restantes postos, os níveis mais elevados de poluição correspondem também às situações com fluxo de direcção indefinida. Contudo, as rosas de poluição dos três

${ }^{4}$ A direcção sinóptica do fluxo, avaliada a partir das cartas sinópticas do Boletim Meteorológico Diário, foi julgada preferível, para esta análise, à direcção do vento em Lisboa/Portela, a qual tem apenas um significado local. Nos casos em que noi foi possível identificar a direcção do fluxo sinóptico, este foi considerado como de "direcção indefinida". 
postos estudados (representando a concentração média de poluentes nas seis horas precedentes à observação, para cada rumo do fluxo sinóptico) evidenciam o transporte de poluentes a partir do centro da cidade (fig. 8); salientam-se os fluxos do quadrante S, para Entre Campos, de N e NE, para a Rua da Prata e de SE, para Benfica.

Apesar de, quando se consideram os valores diários, os níveis de poluição, em Janeiro de 1993, se poderem considerar elevados, verifica-se que os valores médios horários de $\mathrm{NO}_{2}$ só ultrapassaram o limiar de $200 \mu \mathrm{g} / \mathrm{m}^{3}$ (quadro II) em Entre Campos, em $27 \%$ das horas de observação; neste posto, os valores horários foram mesmo superiores a $2000 \mu \mathrm{g} / \mathrm{m}^{3}$, na noite de 9 para 10 de Janeiro. Relativamente ao CO, o limite legal para os valores médios horários (quadro II) foi apenas violado, em Benfica, durante duas horas, entre as 8 e as $10 \mathrm{~h}$ do dia 8 .

$\mathrm{Na}$ maior parte dos dias, verificaram-se os dois picos de poluição característicos às horas de ponta, com os valores da tarde superiores aos da manhã (fig. 6). Contudo, em alguns dias, a variação da concentração dos poluentes apresentou características diferentes; foi o caso de alguns dos dias mais poluídos (8 a 10 de Janeiro, fig. 9).

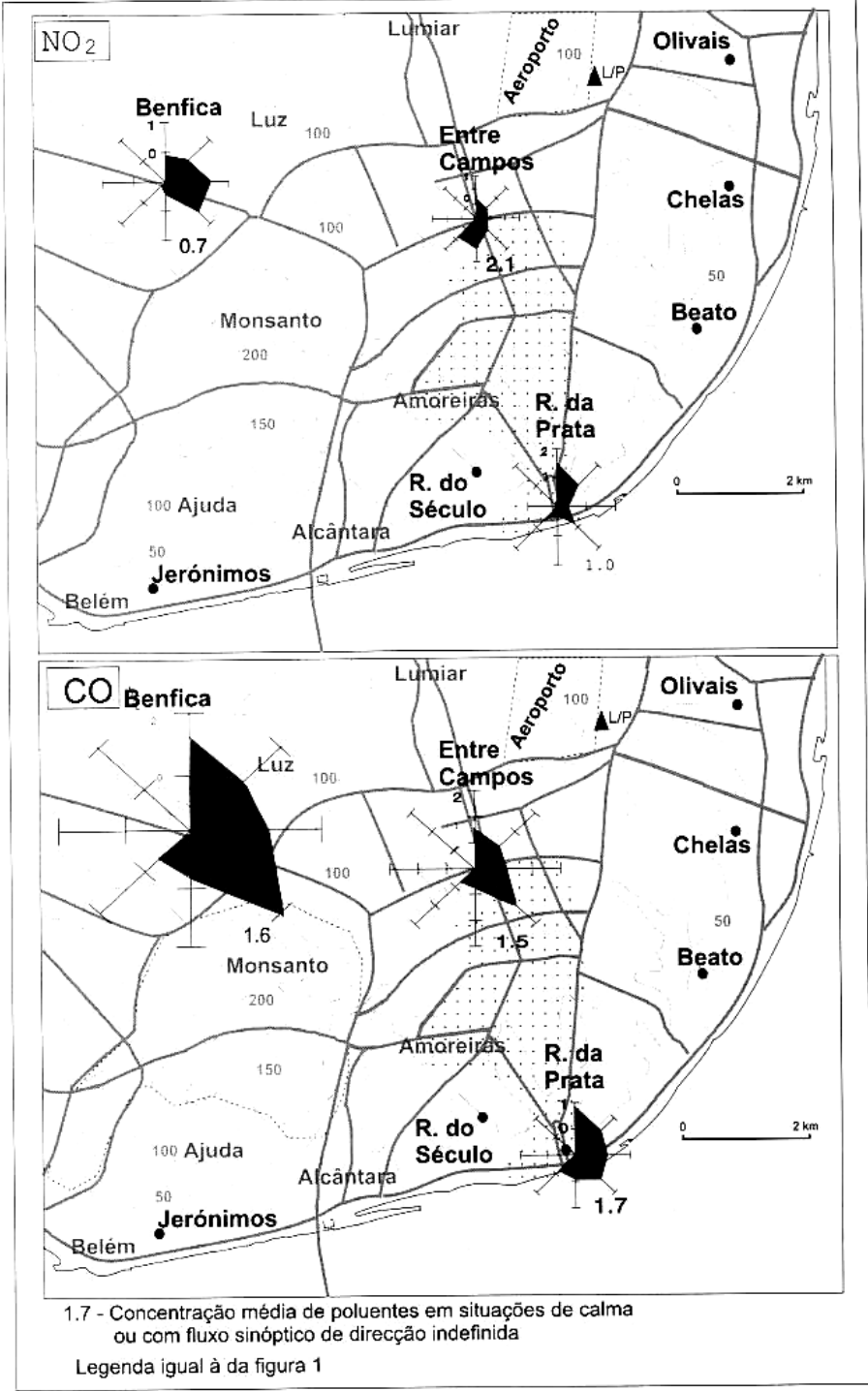

Figura 8 - Concentração média de poluentes por rumo sinóptico do vento, em Janeiro de 1993 (valores normalizados da concentração média nas $6 \mathrm{~h}$ precedentes à observação do fluxo).

Fontes: C.G.A.L.; I.N.M.G.

Figure 8 - Pollution values versus synoptical wind direction in Lisbon, during January 1993 (standardized values). 


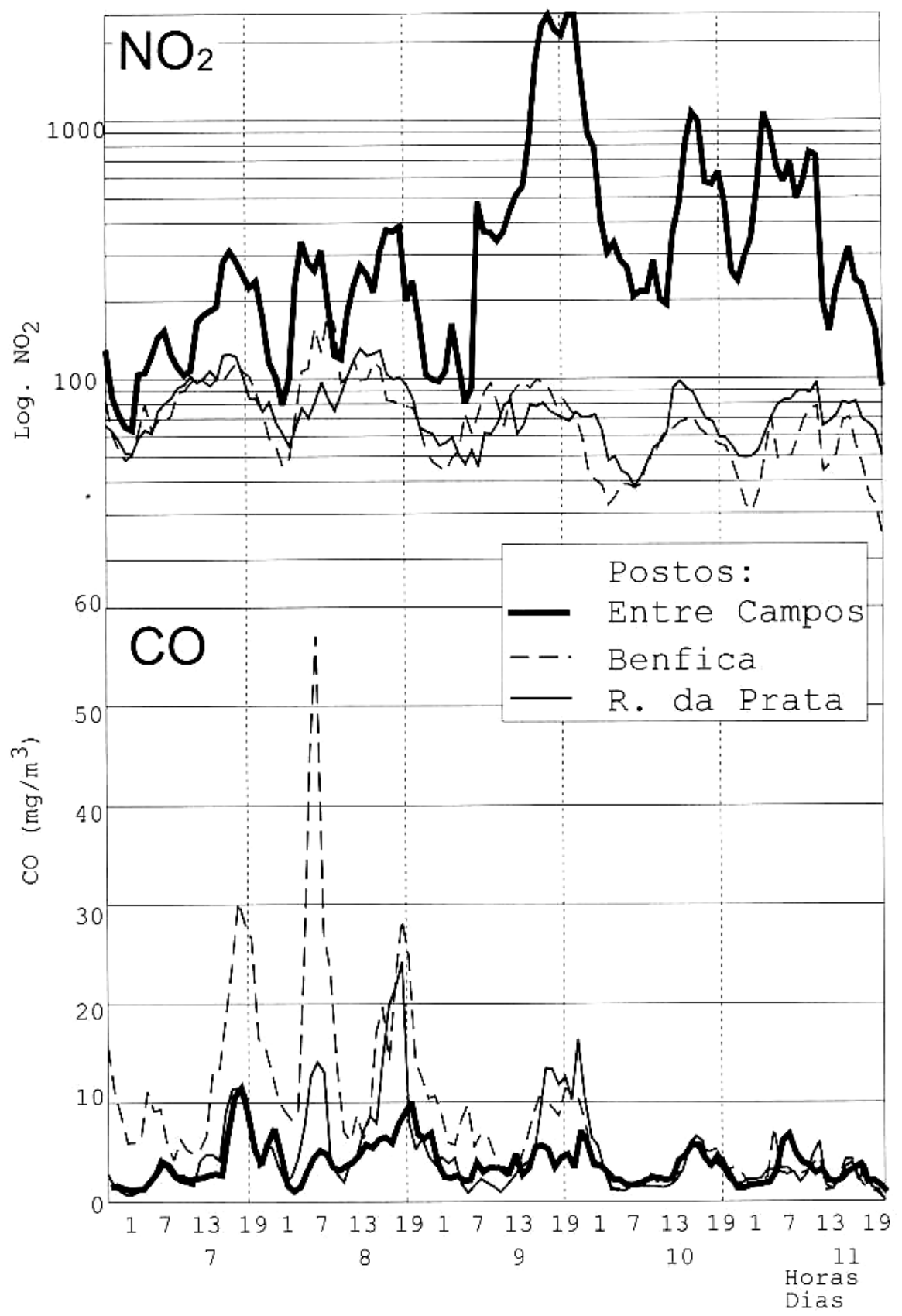

Figura 9 - Concentração média horária de poluentes em Lisboa, entre os dias 7 e 11 de Janeiro de 1993. Fonte: C.G.A.L.

Figure 9 - Mean hourly pollution values in Lisbon, between January the $7^{\text {th }}$ and the $11^{\text {th }}, 1993$. 
Assim, os níveis mais elevados de concentração de monóxido de carbono registados em Benfica, no dia 8 (cerca de $57.1 \mathrm{mg} / \mathrm{m}^{3}$ ) ocorreram por volta das $9 \mathrm{~h}$; contudo nos outros postos, no mesmo dia, os máximos de poluição foram registados à tarde (fig. 9). No dia seguinte, em Entre Campos, não se verificou o máximo da manhã, e a concentração de $\mathrm{NO}_{2}$ atingiu valores extremamente elevados entre as $19 \mathrm{~h}$ e as $2 \mathrm{~h}$ do dia 10 (valores superiores a $2500 \mu \mathrm{g} / \mathrm{m}^{3}$ durante várias horas). $\mathrm{O}$ valor muito elevado de concentração méidia diária de $\mathrm{NO}_{2}$, verificado em Entre Campos, no dia 9, deve-se assim, sobretudo, aos níveis de poluição registados durante o início da noite.

Como já foi referido, não é possível, com os dados disponíveis, explicar estes aspectos particulares da variação horária da concentração de poluentes. Possivelmente, assumiu particular importância a variação no volume de tráfego e, em Entre Campos, a actividade do terminal rodoviário, a qual talvez possa justificar os máximos de poluição muito tardios, registados na noite de 9 para 10 de Janeiro (assim como em várias outras noites, nomeadamente entre os dias 14 e 17). As quatro observações meteorológicas diárias, em Lisboa/Portela, não dão, nestes dias, quaisquer indicações que permitam associar variações das condições de dispersão às da qualidade do ar.

\section{CONCLUSÃO}

Apesar dos níveis de poluição atmosférica não serem, em geral, muito elevados, em Lisboa, regista-se a possibilidade de ocorrência pontual de situações de poluição que ultrapassam os limites legais, devido a condições específicas de emissão e de dispersão. O posto da Rua do Século não parece adequado para caracterizar a qualidade do ar no centro da cidade, sendo evidente que a concentração de $\mathrm{NO}_{2}$ e $\mathrm{CO}$ é inferior à registada noutros postos, mais próximos das áreas de maior emissão de poluentes (Entre Campos, Benfica e Rua da Prata).

Por outro lado, contraria-se a ideia, muito generalizada, de que a área de Lisboa mais afectada pela poluição atmosférica é a Baixa. Níveis mais elevados de concentração de poluentes foram registados em Entre Campos (no caso do $\mathrm{NO}_{2}$ ) e em Benfica (no do CO). Embora o período estudado seja demasiado curto para que se possam tirar conclusões definitivas, o padrão espacial encontrado reflecte a expansão do centro fucional da cidade para $\mathrm{N}$, com deslocamento das actividades terciárias e, naturalmente, o incremento da circulação automóvel, assim como o processo de suburbanização, com aumento do tráfego nas áreas periféricas (os postos de Benfica e Entre Campos situam-se junto a vias de acesso ao centro).

Da análise das variações cíclicas da qualidade do ar, o aspecto mais saliente é um ciclo diário, com dois máximos, às horas de ponta, condicionados provavelmente pela variação no volume das emissões. Quanto à existência de um ciclo anual (em relação ao qual se parece esboçar um máximo de Inverno) ou semanal, é necessária uma análise mais aprofundada.

No estudo do mês de Janeiro de 1993 destacou-se a importância das situações de forte estabilidade atmosférica, no condicionamento dos níveis mais elevados de poluição. Revelaram-se particularmente importantes a velocidade do vento (o limiar de $2 \mathrm{~m} / \mathrm{s}$ em Lisboa/Portela parece delimitar as situações mais poluídas) e a estabilidade vertical da atmosfera (todos os dias mais poluídos tiveram uma inversão térmica sobre Lisboa, às $12 \mathrm{~h}$, a uma altura inferior a $165 \mathrm{~m}$ ). A relação com a direcção do vento é mais complexa, sendo importante a posição do posto relativamente ao centro da cidade. Os níveis de poluição mais forte atingiram-se ou com situações de calma, 
ou com um fluxo favorável ao transporte dos poluentes a partir das áreas de emissão (do quadrante S para Entre Campos, SE a E para Benfica, N para a Rua da Prata).

Evidentemente, muitos aspectos da variação da concentração dos poluentes escapam às explicações que aqui foi possível dar. Esta análise deve ser prosseguida com o estudo de um período mais longo, englobando diferentes episódios de forte poluição e, sobretudo, modificando a escala de análise das condições de dispersão na atmosfera. A utilização de outro tipo de abordagem do problema (nomeadamente a modelização) é também indispensável para o prosseguimento de um estudo deste tipo.

\section{AGRADECIMENTOS}

Devo agradecer à Comissão de Gestão do Ar de Lisboa, a cedência dos dados utlizados neste trabalho. Estou especialmente reconhecido às engenheiras Luísa Nogueira e Teresa Bernardino, pela amabilidade com que fui recebido. Este texto representa um desenvolvimento de uma parte da dissertação de Mestrado (ANDRADE, 1994). Foi iniciado durante um estágio, na Universidade de Liège, integrado no Programa Erasmus. Estou grato ao Professor Michel Erpicum, pela orientação que então me concedeu.

Várias pessoas me ajudaram na conclusão deste artigo, através da sua leitura e crítica; agradeço, neste aspecto, especialmente às Professoras Suzanne Daveau, Maria João Alcoforado, Denise de Brum Ferreira e Maria Eugénia Moreira. Este trabalho foi realizado no âmbito do projecto "Imagens e representações para o ordenamento biofísico em meio urbano: Lisboa", PBIC/C/CEN/1051/92, financiado pela Junta Nacional de Investigação Científiica e Tecnológica, coordenado por Maria João Alcoforado.

\section{BIBLIOGRAFIA}

Alcoforado, M. J. (1987) - Brisas estivais do Tejo e do Oceano na região de Lisboa. Finisterra. Revista Portuguesa de Geografia, XXII (43): 213-225.

AlCOFORADO, M. J. (1988) - O clima da região de Lisboa: vento, nebulosidade e temperatura. Tese de Doutoramento em Geografia Física, Universidade de Lisboa.

Alcoforado, M. J. (1992) - O clima da região de Lisboa. Contrastes e ritmos térmicos. Memórias do Centro de Estudos Geográficos, Vol. 15, Univ. de Lisboa, Lisboa.

ANDRADE, H. (1994) - Poluição atmosférica e clima em Lisboa. Aspectos da variação espacial e temporal no semestre de Inverno. Dissertação de Mestrado em Geografia Física e Regional, Universidade de Lisboa.

BAVAY, R.; I. ROUSSEL. (1991) - Le recul de la pollution atmosphérique d'origine industrielle et domestique dans la Région du Nord-Pas de Calais. Hommes et Terres du Nord, 2-3: 87-96.

BorReGo, C. et al. (1991) Livro Branco sobre o estado do Ambiente em Portugal. M.A.R.N., Lisboa.

CARLIER e Mouvier, 1988 - Initiation à la phisico-chimie de la basse troposphère. Pollution Atmosphérique, Jan-Mar: 12-24.

CÂmara MuniciPAl De LiSBOA (1992) - Plano estratégico de Lisboa. C.M.L., D.P.P.E., Lisboa.

COMISSÃO DE GESTÃo DO AR DE LISBOA (1993) - Relatório técnico. D.R.L.V.T.; M.A.R.N., Lisboa.

COMISSÃO DE GESTÃo DO AR DE LISBOA (1994) - Relatório da qualidade do ar de 1992. D.R.L.V.T., M.A.R.N., Lisboa.

ComRIE, A. C. (1990) - The climatology of surface ozone in rural areas: a conceptual model. Progress in Physical Geography, 14 (3): 297 - 316.

EnVIronmental ProteCtion AgENCY (1971) - Air Quality Criteria for Nitrogen Oxides. Air pollution Control Office, Washington D. C..

Escourrou, G. (1991) - Pollution atmosphérique et vie urbaine. Hommes et Terres du Nord, 4: 241-244 .

FERREIRA, D. de BRUM (1991) - L'atmosphère Terrestre en évolution, incidences et conséquences. L.A.G.F., Rel. no 29 , Centro de Estudos Geográficos, Lisboa.

JANOUEIX-YACONO, D. (1993) - La pollution atmosphérique et ses rapports avec l'environnement biophysique et l'environnement socio-économique. Hommes et Terres du Nord, $\mathrm{n}^{\circ}$ hors série Environnement urbain: 78-91.

JOUMARD, R. (1984) - Le CO traceur de la pollution automobile: Teneurs à l'extérieur et à l'intérieur des véhicules. Pollution Atmosphérique, 103: 182-186. 
MonTEIRO, A. (1988) - Contribuição para o estudo da degradação da qualidade do ar na cidade do Porto. Revista da Faculdade de Letras da Universidade do Porto, IV: 27-63.

MorAN, M. D.; R. V. Portelli (1987) - Atmospheric Transport and Diffusion. in E. E. PiCKETT (ed.). Atmospheric Pollution, Hemisphere Publ. Corporation, Washington: 117 - 127.

OKE, T. R. (1992) - Boundary Layer Climates. Methuen \& Co, London

PaCynA, J. M. (1987) - Sources of Air Pollution. in E. E. PICKETT (ed.). Atmospheric Pollution, Hemisphere Publ. Corporation, Washington: 29-56.

PASQUILL, F. (1974) - Atmospheric diffusion, the dispersion of windborne material from industrial and other sources. Ellis Horwood, Chichester.

PINHO, P; M. J. SeIXAS (1993) - Planeamento Energético e Ambiente. O plano Energético Nacional. Sociedade e Território, 6 (18): 42-56.

PISSIMANIS, D. K.; G. S. KARRAS; V. A. NOTARIDOU (1991) - On the meteorological conditions during some strong smoke episodes in Athens. Atm. Environment, 25B (2): 193-02.

RenouX, A. (1990) - Ce qu'il faut savoir sur l'aérosol atmosphérique. Pollution Atmosphérique, Jan-Mar: 10-13.

RIBAS, R. B. B. (1979) - Dispersão de poluentes na atmosfera. Serviço de Estudos do Ambiente, S.E.O.F.R.H.A., Lisboa.

STROEBEL, R. (1992) - État comparatif de résultats de mesure issus de divers réseaux de surveillance de la poluttion atmosphérique en France, en Europe et en Amérique du Nord, polluants majeurs $\left(\mathrm{SO}_{2}, \mathrm{NO}_{2}, \mathrm{CO}, \mathrm{O}_{3}, \mathrm{~Pb}\right.$ et particules). Pollution Atmosphérique, Jan.-Mar.: 5-23.

VAsConCElos, I.; G. C. NeVEs (1988) - Poluição atmosférica pelos transportes rodoviários. $1^{a}$ Conf. Nacional sobre a qualidade do ambiente, Vol. 2: 653-662

WANTA, R. C. (1968) - Meteorology and air pollution. in A. C. STERn (ed.). Air pollution, Academic Press, New York: 187-225.

Winchester, W. W. (1987a) - Air Acidity and Acid Rain. in E. E. PICKETT (ed.). Atmospheric Pollution, Hemisphere Publ. Corporation, Washington: 69-72.

Winchester, W. W. (1987b) - Wet and Dry Deposition Processes of Gases and Particulate Matter. in E. E. PICKetT (ed.). Atmospheric Pollution, Hemisphere Publ. Corporation, Washington: 65-68. 